\title{
Differences between lung mechanics, respiratory and peripheral muscle strength in former smokers and COPD individuals.
}

\author{
Claudia M M Russi ${ }^{1}$, Alessandra C Toledo-Arruda ${ }^{2}$, Maysa A R Brandao-Rangel ${ }^{3,4}$, \\ Luciano A Chaves ${ }^{5}$, Lucas P Sales-Dias ${ }^{1}$, Tamara Costa-Guimaraes ${ }^{1}$, Susane M M Souza ${ }^{5}$, \\ Regiane Albertini ${ }^{4}$, Luis Oliveira ${ }^{6}$, Ricardo $\mathrm{S} \mathrm{Navarro}^{1}$, Claudio R Frison ${ }^{5}$, and Rodolfo \\ Vieira $^{1}$ \\ ${ }^{1}$ Universidade Brasil \\ ${ }^{2}$ Federal University of Rio de Janeiro \\ ${ }^{3}$ UNIFESP - Universidade Federal de São Paulo \\ ${ }^{4}$ Federal University of Sao Paulo \\ ${ }^{5}$ Brazilian Institute of Teaching and Research in Pulmonary and Exercise Immunology \\ (IBEPIPE) \\ ${ }^{6}$ UniEVANGELICA University Centre of Anapolis
}

April 28, 2020

\begin{abstract}
Background: Reduced peripheral and respiratory muscle strength correlates with impaired lung function in COPD, but whether diminishement in peripheral and respiratory muscle strength correlates with lung mechanis is unknown. Aims: To investigate whether spirometric and respiratory and peripheral muscle strength correlates with small airways obstruction evaluated by impulse oscillometry. Methods: Nighteen COPD GOLD II and twenty former smokers' individuals were evaluated for lung function, lung mechanics, maximum inspiratory and expiratory pressure and hand grip strength test. Results: COPD presented reduced FEV1 and FEV1/FVC $(\mathrm{p}<0.001)$ compared to former smokers with no changes in FVC. In COPD the FEV1 and FEV1/FVC showed a negative correlation with BMI $(\mathrm{P}<0.05, \mathrm{R}=-0.56$ and -0.43 , respectively). The total resistance of respiratory system and small airway resistance were reduced in the COPD compared to former smoke group. The COPD individuals showed a negative moderate correlation between FEV1 and impedance $(\mathrm{R}=-0,664 ; \mathrm{P}<0.01)$; airway resistance $(\mathrm{R}=-$ $0,593, \mathrm{P}<0.05)$ and peripheral airway resistance $(\mathrm{R}=-0,547, \mathrm{P}<0.05)$. The negative correlation was low in $\mathrm{COPD}$ individuals for reactance $(R=-0,434, P<0.05)$ and proximal airway resistance $(R=-0,480, P<0.05)$. These correlations were not found in the former smoke group. Hand grip strength measured in the right arm showed a moderate negative correlation with the maximal inspiratory pressure $(\mathrm{R}=-0,539, \mathrm{P}<0.05)$ in COPD individuals. There was no correlation between PIMax and PEMax with none of the spirometric or oscillometric parameters $(\mathrm{p}>0.05)$ in COPD or former smokers' individuals. Conclusions: Lung mechanics correlate with spirometric parameters in COPD patients but not with respiratory and peripheral muscle strength.
\end{abstract}

\section{What is already known about this topic?}

GOLD II COPD present impaired lung function in comparison to former non-COPD current smokers.

Lung mechanics more precisely can detect structural alterations in the lungs.

Reduced FEV1 in GOLD II COPD correlates respiratory muscle strength.

Impaired respiratory muscle strength correlates with impaired peripheral strength.

What does this article add? 
Lung mechanics alterations more precisely represent structural alterations in the lungs of GOLD II COPD and in former non-COPD current smokers.

GOLD II COPD present impaired lung mechanics, notably for the total resistance of respiratory system and also for small airway resistance compared to former non-COPD current smokers.

Reduced FEV1 in GOLD II COPD correlates with impaired respiratory impedance, proximal and distal airway resistance.

\section{Introduction}

Smoking is one of the main risk factors for the development of chronic obstructive pulmonary disease (COPD). Spirometry is the gold standard and primary method to detect the air flow limitation associated with COPD ${ }^{1}$. Spirometry involves a forced expiratory manouver and the need of patients' cooperation, which may be difficult especially in elderly patients. The COPD severity is graded by forced expiratory volume measured during the first second (FEV1) and the disease treatment is guided also by clinical symptoms and acute exacerbation risk assessment ${ }^{2}$. However, some studies have showed that spirometry presente low specificity and sensitivity to changes in the early stages of chronic respiratory disease ${ }^{3}$.

The multifrequential oscillation techniques, such as impulse oscillometry system (IOS), might be more suitable than spirometry for detecting early stages of respiratory damage. Impulse oscillometry has been used in the clinical practice and as a research tool to measure inspiratory and expiratory flow and pressure during normal tidal breathing over a period of around 30-40 seconds and effort independent. The high frequency oscilation reflects proximal airways resistance and low frequency oscilattions reflects airwas after the eighth airway generation ${ }^{4,5}$. The IOS can be useful to identifying early changes in respiratory system of smokers or even former smokers.

There is a decline of lung function and respiratory mechanics due to aging mainly from 50 to 80 years of age with increased airway resistance ${ }^{6,7}$. Besides the lung fucntion drop, there is an overall decline in skeletal muscle mass, strength and function documented also in respiratory muscle ${ }^{8,9}$. Hand grip strength and maximal static inspiratory and expiratory pressure (MIP and MEP) are recommended as simple tool to measure peripheral and respiratory muscle strength ${ }^{8,10}$.

There is increasing interest in the possible correlations of IOS and spirometry, respiratory and peripheral muscle strength in elderly with COPD and healthy subjects. This study aimed to evaluate the relationship of grip strength and lung function and lung mechanics in elderlies' current smokers versus elderlies with COPD.

\section{Materials and Methods}

\section{Subjects}

This was a prospective study conducted in elderly individuals into 2017. We evaluated 829 individuals aged $>60$ years and 19 COPD GOLD II and 20 non-COPD individuals classified by spirometry were included. COPD were defined by a spirometric result of forced expiratory volume in 1 second $\left(\mathrm{FEV}_{1}\right) /$ forced vital capacity $(\mathrm{FVC})<0.7^{11}$. The inclusion criteria were as follow: individuals with COPD classified with a degree of airflow limitation defined by $\mathrm{FEV}_{1}>50 \%$ and [?]80\% as GOLD $2^{11}$ and non COPD individual matched by age and BMI; sedentary; clinically stable with no change in medication in the last 3 months. A convenience sample of eligible patients were notified in advance about the objectives and procedures of the study and after its approval and signed an informed consent they became part of effective research. This study was approved by the Ethics Committee in Research (53344616.6.0000.5511) of the Brazil University, Sao Paulo, Brazil. The whole study protocol followed the directions gave by Declaration of Helsinki.

Exclusion criteria were met if any participant was unable to meet all of the inclusion criteria, had any contraindication to performing spirometry according to the ATS/ERS guidelines or any other test required for participation in the study ${ }^{12}$. Individuals with history of smoking habit in the last six months, subjects 
with restrictive spirometric pattern ([FEV1/FVC] [?]0.70 and $\mathrm{FVC}<80 \%$ of predicted) or who refused to participate in the study were also excluded.

\section{Study design}

Individuals were evaluated at the "House of Elderly" em Sao Jose dos Campos, Sao Paulo, Brazil, by a first interview conducted to obtainpersonal data, body mass index $\left(\mathrm{kg} / \mathrm{m}^{2}\right)$, smoking history, and spirometry. The participants of this study were evaluated by impulse oscillometry, maximal inspiratory pressure (MIP), maximal expiratory pressure (MEP) and hand grip test. Individuals were instructed not to use pharmacological agents such as anesthetics, analgesics, antidepressants, as well as caffeine-based substances and/or alcohol during the last 12 hours preceding the test. Tests were performed in the morning (from 8 to 9 am) with controlled temperature $\left(24^{\circ} \mathrm{C}\right.$ ) and relative humidity (from 50 to $60 \%$ ).

Spirometry and impulse oscillometry were performed to measure pulmonar function by using Jaeger Masterscreen pulmonary function instrument (Masterscreen IOS, Erich Jaeger, Hoechberg, Germany) in strict accordance with the American Thoracic Society/European Society of Respiratory Diseases guidelines ${ }^{12}$. The reference values for spirometry were specific for the Brazilian population ${ }^{13}$. Total respiratory impedance $(\mathrm{Z} 5 \mathrm{~Hz})$, total resistance of respiratory system $(\mathrm{R} 5 \mathrm{~Hz})$, resistance of proximal/large airways $(\mathrm{R} 20 \mathrm{~Hz})$, resistance of distal/small airways (R5-R20Hz), reactance (X5Hz) and resonant frequency (Fres), were recorded by impulse oscillometry as described previously ${ }^{14}$.

Maximal inspiratory (MIP) and expiratory pressure (MEP) were measured by a pressure transducer (MVD300 V.1.1 Microhard System, Globalmed, Porto Alegre, Brazil). MIP was measured after maximal inspiration effort from residual volume and MEP was measured after residual volume effort from total lung capacity, both against an occluded airway with a minor air leak $(2 \mathrm{~mm})$. The highest pressure of six measurements $(3$ for MIP and 3 for MPE) was used for analysis ${ }^{15}$.

Hand grip strength were measured by a calibrated handheld dynamometer (Jamar ${ }^{\circledR}$, Sammons Preston Rolyan, Boilingbrook, IL, USA) in a supine position. The participants were instructed to sit down with their elbows flexed in an angle of $90^{\circ}$ and three attempts were performed with both hands. The maximum grip recorded value in kilogram was used for analysis ${ }^{16,17}$.

\section{Statistical analysis}

Data were analysed by using SigmaStat 5.0 software (California, USA). Normality of the data was evaluated by the Kolmogorov-Smirnov test and Spearman test for analysis of correlations and the Spearman test interpreted according to Hinkle et. al. (2003) [18]: negligible $0.0-0.3$; low $0.3-0.5$; moderate 0.5-0.7; high $0.7-0.9$; very high $0.9-1.0)$. The data were submitted to a $t$ test for a comparison between the groups Significance values were adjusted to $5 \%(\mathrm{p}<0.05)$. The graphs will be compiled using GraphPad Prism 5.0 software (California, USA).

\section{Results}

\section{Patients selection, inclusion and exclusion}

A total of 829 individuals were screened over 48 months of which 790 were excluded: 90 individuals with asthma; 63 were current smokers, 153 were GOLD 1, 3 or 4, 180 did not complete all exams and 324 were healthy individuals, of which 20 were used in the control group. The 39 eligible individual consented to take part in the study (Figure 1). Patient characteristics are recorded in table 1.

Maximal Inspiratory Pressure (MIP) and Maximal Expiratory Pressure (MEP) and Hand Grip Strength

There was no statistically difference in age, body mass index (BMI), maximal inspiratory pressure (MIP), maximal expiratory pressure (MEP) and hand grip strength in both arm between groups. COPD patients and former smokers presented a percentage of $70.58 \%$ and $57.89 \%$, respectively, of individuals with MIP bellow the reference values. COPD patients and former smokers presented a percentage of $35.29 \%$ and $5.26 \%$, 
respectively, of individuals with weakness in the hand grip strength test (Table 1). In COPD patients there was negative correlation between age and MIP $(\mathrm{P}<0.05, \mathrm{R}=-0.58)$. The MIP was significantly correlated with MEP in former smokers' group with a trend for COPD individuals $(\mathrm{R}=-0,530, \mathrm{P}=0.019$ and $\mathrm{R}=-$ $0,462, \mathrm{P}=0.05$, respectivelly). In both groups the hand grip strength measured in the left arm showed a high correlation with hand grip strength measured in the right arm $(\mathrm{R}=0,959, \mathrm{P}<0.0001$, for former smoke group and $\mathrm{R}=0,899, \mathrm{P}<0.0001$ for $\mathrm{COPD}$ group). Hand grip strength measured in the right arm showed a moderate negative correlation with the maximal inspiratory pressure $(\mathrm{MIP})(\mathrm{R}=-0,539, \mathrm{P}<0.05)$ and a moderate positive correlation with the maximal expiratory pressure $(\mathrm{MEP})(\mathrm{R}=0,586, \mathrm{P}<0.05)$ in $\mathrm{COPD}$ individuals.

\section{Lung Function and Mechanics}

COPD individuals presented reduced FEV1 and FEV1/FVC compared to former smokers' group ( $<<0.001$, Table 2). The airway resistance (resistance at $5 \mathrm{~Hz}$ [R5]) and peripheral airway resistance (R5-R20) were increased in former smokers compared to COPD individuals $(\mathrm{p}<0.05$ and $\mathrm{p}<0.01$, respectivelly, Table 2). There was no statistically difference in impedance, reactance and proximal airway resistance (resistance at 20 $\mathrm{Hz}$ [R20]) between groups (Table 2). However, the COPD individuals showed a negative correlation between FEV1 and FEV1/FVC and BMI $(\mathrm{P}<0.05, \mathrm{R}=-0.56$ and -0.43 , respectively $)$. The COPD individuals showed a negative moderate correlation between FEV1 and impedance $(\mathrm{R}=-0,664 ; \mathrm{P}<0.01)$, airway resistance at $5 \mathrm{~Hz}(\mathrm{R}=-0,593, \mathrm{P}<0.05)$, and peripheral airway resistance ( $\mathrm{R} 5-\mathrm{R} 20 ; \mathrm{R}=-0,547, \mathrm{P}<0.05)$ (Table 3). The negative correlation was low in COPD individuals for reactance $(\mathrm{R}=-0,434, \mathrm{P}<0.05)$ and proximal airway resistance $(\mathrm{R}=-0,480, \mathrm{P}<0.05)$ (Table 3$)$. These correlations were not found in the former smoke group.

\section{Discussion}

Oscillometry is a technique to measure the impedance that comprises airway resistance and reactance. The multifrequential oscillation waves which is transmitted along the tracheobronchial tree typically by 5 and 20 $\mathrm{Hz}$ allow to measure the total airway resistance (at $5 \mathrm{~Hz}$ ), the proximal airway resistance (at $20 \mathrm{~Hz}$ ) and the peripheral airway resistance $(\mathrm{R} 5-\mathrm{R} 20)^{5}$. In the current study, oscillometry detected increased airway resistance in former smokers compared to COPD subjects.

There is also a reduced muscle mass and strength of respiratory muscles. Previous studies demonstrated that in health subjects MIP decreased significantly after 55 years of age ${ }^{19-22}$. In addition, it has been extensively reported that the functional alterations caused by aging such as sarcopenia, mainly in sedentary individuals, contributes to the decrease in respiratory and peripheral muscle strength ${ }^{23,}{ }^{24}$. In the present study no diferences were found in the respiratory strength between COPD (GOLD 2) and former smokers. However average $70 \%$ of COPD and $54 \%$ of former-smokers individuals presented values below the reference values for maximal inspiratory pressure considering age and $\operatorname{sex}^{22}$.

In elderly people the hand grip strength is used as an important functional marker of maintenance of functional independence and quality of life and reduced levels of grip strength can predict disability or mortality ${ }^{25}$. The grip strength less than $26 \mathrm{~kg}$ in men and less than $16 \mathrm{~kg}$ in women aged 65 and older are considered "weak" 26 .

Two previous meta-analyses provided the reference values for grip strength in the general population 27,28 . In our study $35.29 \%$ of COPD patients and $5.26 \%$ of former smokers presented a weakness in hand grip strength based on age and sex. A recent study reported that the risk for mortality from COPD was higher per $5 \mathrm{~kg}$ lower in grip strength ${ }^{29}$. With increasing age there is a decrease in pulmonar function with a decrease in forced expiratory volume in 1 second (FEV1), forced vital capacity (FVC), and forced expiratory flow decrease ${ }^{30,31}$.

Interestingly former smokers showed increased airway resistance and peripheral airway resistance compared to COPD group. The forced expiratory volume in the first second is not the best tool to access small airway resistance. For these analyses the preference variable is the maximal expiratory flow (25-75\%) especially for evaluation of asthmatic patients as the disease since, during the initial blow, the chokepoint is central 
and MEF is mostly unaffected by peripheral airway resistance. This forms the basis of using mid or late expiratory flows (MEF 25-75) as an index of peripheral/small airway disease. However, this too is shown to be inadequate.

Respiratory impedance is the sum of all forces which oppose the generated impulse. Impedance measured at any frequency is the ratio of the difference in pressure and changes in the flow at that frequency. Depending on the region where the pressure is measured, the impedance varies. For example, pressure difference at the mouth and in the alveoli gives impedance of the airways and the difference at the mouth, and pleural pressures give a total impedance of the lung. In IOS, the pressure measured at the mouth is compared to atmospheric pressure, which is the pressure outside the chest wall. This defined as respiratory system Zrs and includes the in-phase (real) component which is the resistive component (Rrs) and an out-of-phase (imaginary) component which is a reactive component (Xrs). Simply put, Rrs can be viewed as the energy dissipation whereas Xrs as energy storage. Since IOS measures input impedance, abnormalities of chest wall and skeletal muscles will also be reflected in the measurement.

\section{Conclusion}

We conclude that the parameters measured by IOS correlate with spirometric parameters in COPD patients but not with respiratory and peripheral muscle strength.

\section{Declaration of Competing Interest}

The authors declare that they have no conflict of interest.

\section{REFERENCES}

1. Kaminsky DA. What does airway resistance tell us about lung function?Respir Care . 2012;57:85-99. https://doi: 10.4187/respcare.01411.

2. Global Initiative for Chronic Obstructive Lung Disease (GOLD). Global strategy for the diagnosis, management, and prevention of chronic obstructive pulmonary disease. 2017. [Accessed August 16, 2018]. Available from: http://www.goldcopd.org.

3. John DP, Walters JAE, Walters EH. Diagnosis and early detection of COPD using spirometry. J Thor Dis . 2014;6:1557-1569. https://doi: 10.3978/j.issn.2072-1439.2014.08.18.

4. Michaelson ED, Grassman ED, Peters WR. Pulmonary mechanics by spectral analysis of forced random noise. J Clin Invest . 1975:56:1210-1230. https://doi: 10.1172/JCI108198.

5. Winkler J, Hagert-Winkler A, Wirtz H, et al. Modern impulse oscillometry in the spectrum of pulmonary function testing methods,Pneumologie . 2009;63:461-469. https://doi: 10.1055/s-00291214938.

6. Niewoehner DE, Kleinerman J. Morphologic basis of pulmonary resistance in the human lung and effects of aging. J Appl Physiol . 1974;36:412-418. https://doi.org/10.1152/jappl.1974.36.4.412

7. Turner JM, Mead J, Wohl ME. Elasticity of human lungs in relation to age. J Appl Physiol . 1968;25:664-671. https://doi.org/10.1152/jappl.1968.25.6.664

8. Ohara DG, Pegorari MS, Oliveira Dos Santos NL, et al. Respiratory muscle strength as a discriminator of sarcopenia in community-dwelling elderly: A cross-sectional study.J Nutr Health Aging . 2018;22:952-958. https://doi.org/10.1007/s12603-018-1079-4

9. Summerhill EM, Angov N, Garber C, et al. Respiratory muscle strength in the physically active elderly. Lung . 2007;185:315-320. https://doi.org/10.1007/s00408-007-9027-9.

10. Cruz-Jentoft AJ, Baeyens JP, Bauer JM, et al. Sarcopenia: European consensus on definition and diagnosis: Report of the European Working Group on Sarcopenia in Older People. Age Ageing . 2010;39:412-423. https://doi.org/10.1093/ageing/afq034.

11. Singh D, Agusti A, Anzueto A, Barnes PJ, Bourbeau J, Celli BR, Criner GJ, Frith P, Halpin DMG, Han M, Lopez Varela MV, Martinez F, Montes de Oca M, Papi A, Pavord ID, Roche N, Sin DD, Stockley R, Vestbo J, Wedzicha JA, Vogelmeier C. Global Strategy for the Diagnosis, Management, and Prevention of Chronic Obstructive Lung Disease: the GOLD science committee report 2019. Eur Respir J . 2019;53(5). pii: 1900164. https://doi: 10.1183/13993003.00164-2019. 
12. Graham BL, Steenbruggen I, Miller MR, Barjaktarevic IZ, Cooper BG, Hall GL, Hallstrand TS, Kaminsky DA, McCarthy K, McCormack MC, Oropez CE, Rosenfeld M, Stanojevic S, Swanney MP, Thompson BR. Standardization of Spirometry 2019 Update. An Official American Thoracic Society and European Respiratory Society Technical Statement.Am J Respir Crit Care Med . 2019;200(8):e70-e88. https://doi: 10.1164/rccm.201908-1590ST.

13. Rufino R, Costa CH, Lopes AJ, Maiworm AI, Maynard K, Silva LM, Dias RM. Spirometry reference values in the Brazilian population.Braz J Med Biol Res . 2017;50(3):e5700. https://doi: 10.1590/1414$431 X 20175700$.

14. Wei X, Shi Z, Cui Y, et al. Impulse oscillometry system as an alternative diagnostic method for chronic obstructive pulmonary disease. Medicine (Baltimore). 2017;96:e8543. https://doi.org/10. 1097/MD.0000000000008543. American Thoracic Society/European Respiratory Society. ATS/ERS Statement on respiratory muscle testing. [Accessed August 16, 2018]. Am J Resp Crit Care Med . 2002;166:518-624. https://doi.org/10.1164/rccm.166.4.518

15. Kim Nan-Soo. Correlation between grip strength and pulmonary function and respiratory muscle strength in stroke patients over 50 years of age. J Exerc Rehabil . 2018;14:1017-1023. https://doi. org/10.12965/jer. 1836444.222

16. Mathiowetz V, Weber K, Volland G, et al. Reliability and validity of grip and pinch strength evaluations. J Hand Surg Am . 1984;9:222-226. https://doi.org/10.1016/s0363-5023(84)80146-x. Hinkle, Wiersma, \& Jurs (2003). Applied Statistics for the Behavioral Sciences (5 thed.). Celli BR, Decramer M, Wedzicha JA, et al. An Official American Thoracic Society/European Respiratory Society Statement: Research questions in chronic obstructive pulmonary disease. Am J Resp Crit Care Med . 2015;191:4-27. https://doi.org/10.1183/16000617.00000315

17. Black LF, Hyatt RE. Maximal respiratory pressures: normal values and relationship to age and sex. Am Rev Respir Dis . 1969;696-702. https://doi.org/10.1164/arrd.1969.99.5.696.

18. Bahat G, Tufan A, Ozkaya H, et al. Relation between hand grip strength, respiratory muscle strength and spirometric measures in male nursing home residents. Aging Male . 2014;17:136-140. https: //doi.org/10.3109/13685538.2014.936001.

19. Pessoa IMBS, Parreira VF, Fregonezi GAF, et al. Reference values for maximal inspiratory pressure: A systematic review. Can Resp J . 2014;21:43-50. https://doi.org/10.1155/2014/982374.

20. Goodpaster BH, Park SW, Harris TB, et al. The loss of skeletal muscle strength, mass, and quality in older adults: the health, aging and body composition study. J Gerontol A Biol Sci Med Sci . 2006;10:1059-1064. https://doi.org/10.1093/gerona/61.10.1059.

21. Holmes SJ, Allen SC, Roberts HC. Relationship between lung function and grip strength in older hospitalized patients: a pilot study. Int J Chron Obstruct Pulmon Dis . 2017;12:1207-1212. https: //doi.org/10.2147/COPD.S120721.

22. Ganna A, Ingelsson E. Five-year mortality predictors in 498,103 UK Biobank participants: a prospective population-based study. Lancet . 2015;386:533-540.

23. Alley DE, Shardell MD, Peters KW, et al. Grip strength cutpoints for the identification of clinically relevant weakness. J Gerontol A Biol Sci Med Sci . 2014;69:559-566. https://doi.org/10.1016/ S0140-6736(15)60175-1.

24. Bohannon RW, Peolsson A, Massy-Westropp N, et al. Reference values for adult grip strength measured with a Jamar dynamometer: a descriptive meta-analysis. Physiotherapy . 2006;92:11-15. https: //doi:10.1016/j.physio.2005.05.003.

25. Bohannon RW, Bear-Lehman J, Desrosiers J, et al. Average grip strength: a meta-analysis of data obtained with a Jamar dynamometer from individuals 75 years or more of age. J Geriatr Phys Ther . 2007;30:28-30.

26. Celis-Morales CA, Welsh P, Lyall DM, et al. Associations of grip strength with cardiovascular, respiratory, and cancer outcomes and all cause mortality: prospective cohort study of half a million UK Biobank participants. BMJ . 2018;8:361. https://doi.org/10.1136/bmj.k1651.

27. Janssens JP, Pache JC, Nicod LP. Physiological changes in respiratory function associated with ageing.Eur Respir J . 1999;13:197-205. https://doi.org/10.1034/j.1399-3003.1999.13a36.x 
28. Janssens JP. Aging of the respiratory system: impact on pulmonary function tests and adaptation to exertion. Clinic and Chest Medicine . 2005;26:469-484. https://doi.org/10.1016/j.ccm.2005.05. 004

\section{Figure Legends}

Figure 1. Flowchart for the recruitment into the study.

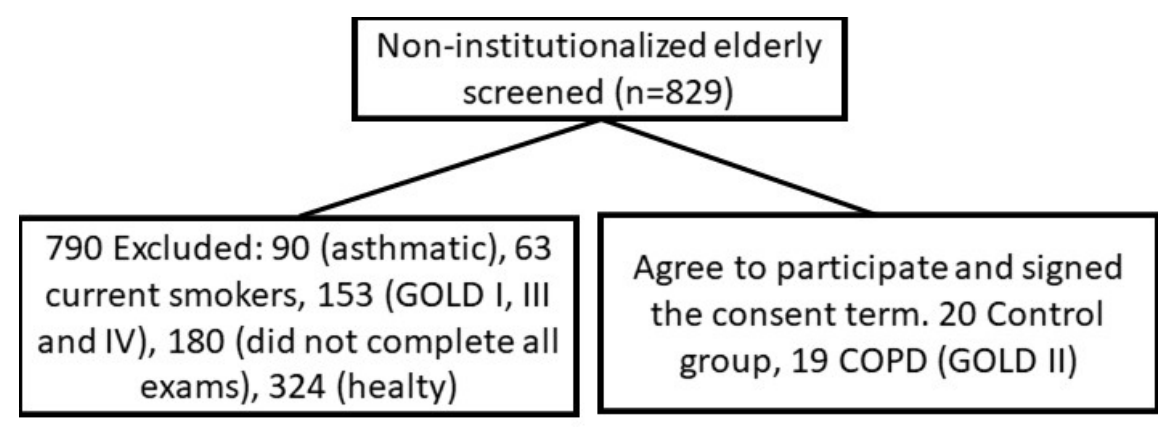

\section{Hosted file}

Table 1.docx available at https://authorea.com/users/308545/articles/441522-differences-betweenlung-mechanics-respiratory-and-peripheral-muscle-strength-in-former-smokers-and-copd-individuals

\section{Hosted file}

Table 2.docx available at https://authorea.com/users/308545/articles/441522-differences-betweenlung-mechanics-respiratory-and-peripheral-muscle-strength-in-former-smokers-and-copd-individuals

\section{Hosted file}

Table 3.docx available at https://authorea.com/users/308545/articles/441522-differences-betweenlung-mechanics-respiratory-and-peripheral-muscle-strength-in-former-smokers-and-copd-individuals 